\title{
The Impact of E-Learning Technologies on Student's Motivation: Student Centered Interaction in Business Education
}

\author{
Almaz Sandybayev* \\ The Higher Colleges of Technology
}

*Corresponding Author: Almaz Sandybayev, The Higher Colleges of Technology

\begin{abstract}
In the past two decades, the development of new information technology has brought significant changes in all areas of society. Accordingly, the rhythm of a contemporary life and the process of interaction with the outside world has been accelerated. The use of the Internet has allowed the creation and development of remote employment of people, providing them with access to information and educational resources throughout the world. These changes have inevitably affected education, as evidenced by the increasingly frequent use of teachers and students themselves to Internet resources, Internet services, various online educational programs and installed applications and other forms of distance learning.

The study investigates the effectiveness of using E-Learning technologies in teaching in the United Arab Emirates public institution using Blackboard Leaning. BBL is a web-based server software which emphasizes course management and scalable design that allows integration with student information systems and authentication protocols. BBL has been implemented in researched higher education institution and used as a tool to deliver e-content. Additionally, BBL provides faculty to add resources for students to access online courses for students to enhance teaching and learning efforts.

The paper analyzes motivation of students towards using E-Learning approach as a crucial factor in learning and especially in business education learning environment. In particular, the utilization and active use of interactive features as BBL increases motivation and as a result leads to better learning results.
\end{abstract}

Keywords: E-Learning, E-Learning technology, motivation, student centered interaction.

\section{INTRODUCTION}

The use of computer technology, the introduction of information technology in all branches of contemporary production, in everyday life and social life are integral features of every society (Prensky, 2007, Housand and Housand, 2012, Thomas, O’Bannon, and Bolton, 2013).

These changes could not affect the entire education system. Acknowledging the introduction of information technologies into the learning process, unlimited possibilities appeared for individualizing and differentiating of the learning process, reorienting it to the development of thinking and imagination as the main processes necessary for successful learning. The ability to work on a computer provides an effective organization of students' cognitive activity. Improving the quality of training and the effectiveness of knowledge. The teacher and the students are active parties and stakeholders in the educational process where this interaction takes place. Interaction is an essential characteristic of the educational process, a special type of relations between its subjects, a process of activity and personal exchange between teachers and students, a constantly evolving process of integration activities of subjects, including the target, motivational, activity, process aspects. Undoubtedly that motivation becomes an essential part of the learning process where teacher-students interaction has a rigorous role. Promoting motivation to learn is one of the main principles for efficient education (Kim and W. Frick, 2011).Some research works indicate the relationship between student's motivation and technology based environment (Roblyer and Doering, 2010). Wilkinson (2016) argued that using media resources as YouTube better enhances student's motivation and work.O'Neil, Wainess and Baker (2005) tend to reveal that combined method of gaming impacts positively on the level of interaction and motivation. All these approaches and methods hold that it is crucial to produce the learner's motivation.

Pedagogical interaction is a special form of communication between the participants of the educational process, in the course of which the intellectual, emotional and activity spheres of the 
participants of this process are enriched. It is necessary to properly build this interaction by creating favorable conditions for learning, promoting the personal development of the student and student's self-realization. According to Lucas and Moreira (2009); Song and Bonk (2016), ICT can escalate students' motivation in self-directed learning aspects when using online learning resources. The newest humanistic paradigm of education implies a transition to a student-centered approach. The student becomes the central figure of the educational process. With a student-centered approach, the main outcome of the educational process is learning outcomes in terms of knowledge, understanding and abilities, and not the means and teaching methods that teachers use to achieve these results. Student-centered learning becomes in avant-garde of development of learning approach where students activities are important indicators in learning process and quality of learning product (Zohrabi, et al., 2012). There is a shift of emphasis from teaching to teaching as an active educational activity of a student. As claimed by Wohlfarth et.al, (2008), in a learner-centered classroom, teachers abandoned lecture notes and power point presentations for a more active, engaging, collaborative style of teaching. The student-centered approach takes into account personal characteristics and needs of students, focuses on independent activities and reflection, on increasing personal responsibility for learning outcomes. This changes the role of the teacher. The teacher needs to form partnerships with the student, allowing him or her to achieve clarity and transparency of requirements, not only to the level of academic achievements but also to control procedures. It is necessary to establish "feedback" with the student and to make learning outcomes and their analysis available to all interested parties.In this approach, the role of teacher remains a helper, facilitator, mentor (Ang, Gonzalez, Liwag, Santos and Vistro-Yu, 2001) and a guide whereas student's role remains central in the whole process. Along with the preservation of its former role-playing status, the teacher is designed to provide higher levels of counseling and motivation of students in what is related to the critical selection of information, its sources, the organization of adequate learning situations and the elimination of identified gaps. The teacher is increasingly implementing the new function of the student's leader and consultant in the matter of acquiring various competencies, becoming a 'systematizer' of knowledge and a curator of the students. In turn, the educational process requires students to be more involved, to develop their skills to work with original information, to use various forms of access to information and its assessment.

Realization of these directions is possible due to the introduction of innovations in the educational process. This is a basis for teaching in active and interactive forms and methods of teaching, which make it possible to intensify the educational process, since they are built on the dialogue and cooperation of all subjects of study. Examples of active and interactive forms and methods are: technology for developing critical thinking, dialogue technology, technology for project activities, modular, contextual and problem-based learning. Wlodkowski (2005) argues that learners receive more knowledge and skills by acquiring computer-based technology in comparison to traditional classroom methods. In this direction, undeniably, a special role belongs to information and communication technologies (ICT) which act as a catalyzer of interactive learning. Information technology is a combination of modern computer technology, telecommunications equipment and software tools that provide interactive support for contemporary learning technologies. Wan, Wang, and Haggerty (2008) in their study claimed that having experience with ICT and virtual competence were two important elements that affected e-learning and had a positive influence on its results. ICTs include a wide range of digital technologies used for creating, transmitting and distributing information and providing services: computer equipment, software, telephone lines, cellular communications, electronic mail, cellular and satellite technologies, wireless and cable communications networks, multimedia, Internet tools. ICT tools contribute to the formation of a new information and educational environment as a basis for the development and improvement of the education system. With the help of ICT network tools, new opportunities are opening up: access to modern information and educational resources, educational and methodical and scientific information, wide use of training programs and electronic textbooks, organization of operational consulting assistance, simulation of research activities, conducting virtual training sessions (seminars, lectures) in real time. Modern ICTs have expanded the possibilities of programmed and distance learning.

\section{LITERATURE REVIEW}

\subsection{E-Learning as a Trend In Education}

In the conditions of the information society, significant attention is paid to the development of lifelong education which allows to solve a number of problems associated with the formation of a new 
information culture, with a changing educational paradigm focused on the development of a creative personality, on the transition from the assimilation of prepared knowledge to design, search activities. The transition to a continuous, open education is one of the ways to resolve the contradictions between the developing culture and the traditional way of human education. E-learning (electronic learning, e-learning, EL), which allows universities to meet the growing global demand for educational services, becomes a determined support. E-Learning as a concept covers a range of applications, learning methods and processes (Rossi, 2009). Authors, Oblinger and Hawkins (2005) noted that E-Learning has been remodeled from online courses to using technology to deliver part or all of a course independently. In recent years, E-Learning technologies have become an integral part of the educational process in universities and colleges and are commonly used in all forms of education. According to Maltz et al (2005), the term 'E-Learning' is applied in different perspectives, including distributed learning, online-distance learning, hybrid and mobile learning.

E-Learning have taken an active position among ICT tools with the help of which it is possible to carry out electronic interaction. The use of E-Learning allows to improve the quality of education through the use of rapidly replenishing world educational resources and due to the fact that the use of E-Learning elements and distance educational technologies increases the share of independent work of students during mastering the material. Especially important for E-Learning was the introduction of educational standards of the new generation and the associated reduction in the volume of classroom work, increasing and expanding the forms of independent work of students, for which E-Learning opens up new opportunities. Results by O'Neill et al. (2011) revealed that students taking e-learning were more optimistic about the learning experience.

The introduction of E-Learning system into the educational practice of a classical university is a long and complex process, the organization of which requires a systematic approach, including: infrastructure creation - creation and development of technical, technological, organizational and methodological conditions for the introduction of E-Learning - staffing of the process of developing, implementing and co-conducting automated training process management systems $\bullet$ research work aimed at exploring the possibilities of information technologies used in the educational process, adapting new technologies to the conditions of the university or higher education institution, studying psychological, educational, ergonomic and other aspects of introducing E-Learning; educational technologies and their introduction into the educational process, the development of methodologies • training and systematic support of teachers $\bullet$ a system of motivation for teachers and students to work in E-Learning - development of electronic educational resources and automated tools to support the learning process $\bullet$ monitoring learning outcomes and process quality.

\subsection{The Higher Education Institution as a Flagman of Virtual Learning Environment}

The researched public HE Institution uses Blackboard Learn 9.1 (BBL) as a communication and content sharing platform for faculty and students. BBL has a significant number of features to assist faculty engage students online. The objectives of E-Learning at researched institution mainly are: shaping the information culture of students and teachers; creating an intellectual portfolio of programs that provide international competitiveness; introducing new educational programs together with leading universities and research organizations. The standard BBL content consists of:

- Course content: This feature allows teachers to post articles, assignments, videos.

- Calendar: Teachers can use this function to post due dates for assignments and tests.

- Learning modules: This feature is often used for strictly online classes. It allows professors to post different lessons for students to access.

- Assessments: This tab allows teachers to post quizzes and exams and allows students to access them via the internet.

- Assignments: This feature allows assignments to be posted and students to submit assignments online.

- Grade Book: Teachers and professors may post grades on Blackboard for students to view.

- Media Library: Videos and other media may be posted under this function. 
This interactive technology of creating online courses in the HEI format can be used when working with students, as well as in the system of additional education, allows the university, on the one hand, to be included in the system of global education and work with students from around the world, on the other hand, the courses act as an effective marketing tool for attracting talented and gifted young people to study at university. The maintenance of E-Learning in education, especially in HEI's has a number of gains. Several authors provided advantages evolved from the adoption of E-Learning technologies in schools curricular (Algahtani, 2011; Hameed et al, 2008; Marc, 2002).Thus, new pedagogical technologies and tools make it possible to create a fundamentally new shell for educational material that meets the trends of the time.

\subsection{Traditional form of Education and E-Learning: Contradiction or Opportunity?}

It is also necessary to note that information technologies and E-Learning will not be able to completely replace the traditional form of education, ousting the teacher from education. They are designed to change the nature of interaction between the teacher and student, their role in the educational process. With E-Learning, a teacher instead of translating ready-made knowledge is transformed into a consultant, a tutor who helps a student to build an individual learning trajectory, to teach for gaining knowledge. Students, in turn, collaborate from passive consumers of an educational product into active participants in the process of creating and accumulating new knowledge. In addition, modern technologies cannot fully replace the student's live communication with a teacher (at least for now), conducting a series of practical exercises that require the full-time presence of participants in the educational process in the audience. Rovai, Ponton, Wighting and Baker (2007) study on student's motivation proved that e-learners were more motivated than students with traditional class view. Therefore, blended learning is considered as the most effective and promising practice, the so-called mixed (or combined) training based on a combination of E-Learning principles and technologies and traditional classroom training. At the same time, the combined training is also becoming more diverse, suggesting simultaneous classes for a distributed audience, when some students are in a regular classroom with a teacher; some are connected to an online class (webinar, video conference, Skype) from home computers or from a remote audience. Moreover, part of the students who for various reasons could not participate in the online class, with this training, it is possible to study the material using offline technologies - through the distance learning system, having access to educational materials, webinar videos, practical tasks, etc. Blended learning involves the organization of students' independent work through the massive use of electronic courses developed in various environments, virtual and remote laboratory complexes, distance learning systems, social networks, mobile platforms, partial transfer of certain types of classes to a virtual electronic environment and organization of project activities in it. At the same time, it is possible to assume that E-Learning, in spite of the advantages that it has also has some disadvantages. Studies argue that E-Learning possesses some disadvantages (Collins et al. 1997; Klein and Ware, 2003; Hameed et al, 2008).

The process of introducing E-Learning in a classical university is complicated by a large proportion of the humanitarian areas of training, whose teachers are often extremely critical towards the processes of informatization in general and are reluctant to turn to information technology. At the same time, in recent years, a number of additional external and internal incentives for the introduction of $\mathrm{E}$ Learning have emerged: E-Learning regulation, state policy, development of information culture and ICT, academic mobility, the introduction of new educational standards providing for the reduction of auditorial work and expansion of independent work students. The massive introduction of E-Learning in universities and colleges significantly accelerates the development of mobile and tablet technologies (M-Learning) which are based on the use of portable devices (mobile phones, smartphones, tablets) and wireless communication channels (WAP, GPRS, Wi-Fi). Mobile technologies open up access to educational resources anytime and anywhere; their important feature is their "preparedness" for the creation of an individual educational route: the choice of educational content with regard to personal interests.

\subsection{Issues of Student's Motivation in an E-Learning Environment}

Technology can promote motivation by engaging students in activities which are enjoyable and fulfilling (Huang et al, 2016; Golonka et al, 2014).Isa Figueira and Manuel Duartes' (2011) study indicates that, students eager for education, prefer to obtaina higher quality of learning and 
demonstrate that the quality of the learning product enhanced with the interference on motivation. Observing motivation issues of students' work in E-Learning systems, it is worth noting that very often apart of high motivation, low motivation to learn is itself disguised by disregard for any ELearning systems. Therefore, it is necessary to clearly distinguish the reason why students are dissatisfied when working with online learning systems, what is the nature of these negative reactions. According to Yang and $\mathrm{Wu}$ (2012), technology-based activities must focus on goals to create students' interest and increase their willingness to participate. Therefore, within the framework of this article, it is important to discuss work motivation in E-Learning systems, taking into account the initial average student's motivation for learning, characterized by such a qualitative subjective assessment, as "satisfactory". As argued by Woodrow (2017), technology environment has a multiple effect on student's motivation and leads them to acquire better results. The ratio of total motivation to learning with work motivation in electronic systems is clearly seen in the following example. On the base of one of the public institutions, it was found that the main annoying factors when students work in E-Learning are technical errors and failures. At the same time, there was a direct dependence of the degree of this irritation on the motivation to learn. Considering the generally low (but satisfactory) degree of motivation of the main stream of most of the nowadays students, the first conclusion should be made: distance and E-Learning systems should work flawlessly from a technical point of view, i.e. correctly save and reproduce the necessary information. At the same time, the requirements for the quality of the interface are not as critical as the requirements for correct operation and ensuring data integrity. Any systematic error, such as regular system hangs during testing, instantly generates a wave of anger among students who are poorly motivated to learn and this general discontent is rapidly passed on to the entire contingent of students. As for the requirements for the interface of E-Learning systems, then everything is forgivable, except for those elements that can be annoying. Apart from, this requirement fully reflects the modern requirements for web design of sites where aesthetic value is no longer as important as ergonomics, "clarity", user-friendly interface and absence of irritating factors. Currently, the main factor is the presence of the expected high-quality content. The resource must correctly provide the required information and not annoy by the interface elements. For example, annoying elements may include entering a password repeatedly, as it happens during Faculty Wide Assessment exams. Of course, special settings of browsers can solve this problem but a fullfledged system should work when delivered "As Is", without the need for additional settings in browsers.

Another factor reducing the motivation of students in E-Learning systems is a "fear of everything new," a kind of IT-xenophobia, caused, on the one hand, by low computer literacy and on the by certain conservatism. An observance practice indicates that students recently started their education as first year students, experienced serious stress when introducing electronic learning systems. The number of dissatisfied participants in the experiment was close to $\underline{70-80 \%}$ of the total number of students in the group. At the same time, students from the third year adapted to the BBL system and requirements, readily accepted E-Learning and overwhelmingly found this experience useful (already $80-90 \%$ of students found significant benefits and usability of E-Learning systems). To reduce information and technological xenophobia, in the author's opinion, motivational techniques can be applied, based precisely on the role of the teacher's personality, as a leading factor of success for student's motivation. Bhuasiri, Xaymoungkhoun, Zo, Rho and Ciganek (2012) believe that key imperatives for implementing effective e-learning are technology awareness, motivation, and changing learners' behavior.

\section{RESEARCH METHODOLOGY}

\subsection{Questions and Hypothesis of the Study}

The key questions of this study were to measure to what extent using the interactive features of ELearning may increase the motivation of undergraduate students for the learning process. For this reason, the present study aims to answer the following research hypothesis:

H1. Is there any statistically significant difference between students indicating interest towards online activities and E-Learning process as opposed to traditional 'face-to-face' method of learning.

$\mathrm{H} 2$. Is there any statistically significant difference between students indicating interest towards online activities and E-Learning process based on the students' degree year. 
The Impact of E-Learning Technologies on Student's Motivation: Student Centered Interaction in Business Education

\subsection{Design, Population and Instrumentation}

This research was conducted in 2019 in Abu Dhabi, UAE, based on one of the leading public institutions. The studied HEI has introduced E-Learning as a learning tool to support traditionally delivered classes with relevant online and E-Learning experience. The total population in this study was 98 students who were examined through quantitative data analysis using descriptive statistical analysis. Then the data was analyzed using the SPSS 16.0.software to compute descriptive statistics and frequency tables.

The sample group was provided with a questionnaire survey which has been adapted from Cheng (2006) and contained twelve questions with five different scales (Strongly Agree $=5$ points, Agree $=4$ points, Neither Agree or Disagree $=3$ points, Disagree $=2$ points, Strongly Disagree $=1$ points) for each question.

The questionnaire survey mainly estimated the students' willingness to utilize and operate E-Learning to measure attitudes towards E-Learning for some specific classes. Table I represents the questionnaire form used. Additionally, to seek the diversified factors that impact students' motivation towards E-Learning, the group has been requested to select between paper-based and web-based assignments.

Out of 118 distributed questionnaires, 78 questionnaires were completed and validated for further research. It is important to note that all participated students were from Business Faculty and registered between 2015-2018 years.

\subsection{Research Model}

The research concept describes how E-Learning impacts on students' motivation and indicates this relationship.
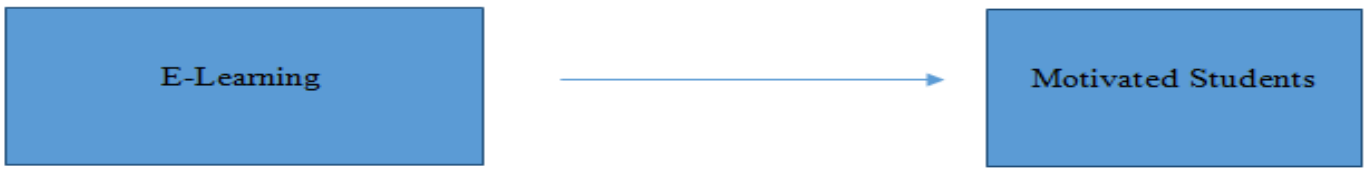

\section{RESULTS AND DISCUSSION}

Based on the results from the table, for $\mathrm{H} 1$, the results exposed a significant difference between the students who had chosen web and paper-based assignments by answering questions 1, 6, 7, 8 and 9 . (Table1).

For $\mathrm{H} 2$, the mean scores for degree year one were higher except for questions 3 and 12 . The results revealed that for these two questions the mean scores were higher for the preparatory year. There was a significant difference $(\mathrm{p}<0.05)$ for questions 5, 6, 11 and 12 (Figure 2). Thus, two above hypothesis H1 \& H2 had been accepted.

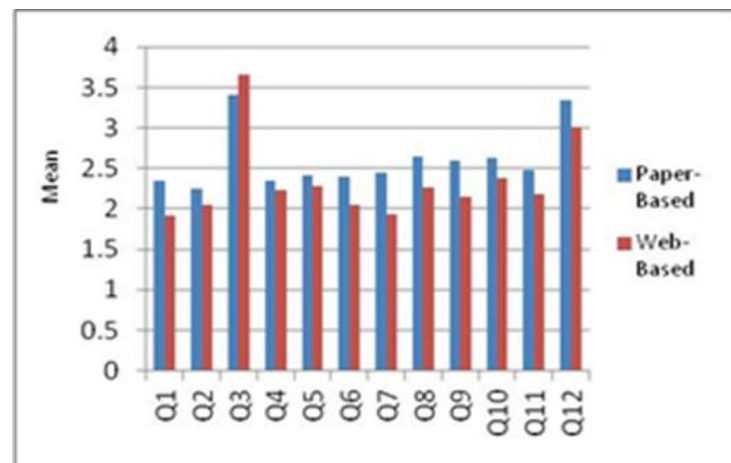

Figure1.

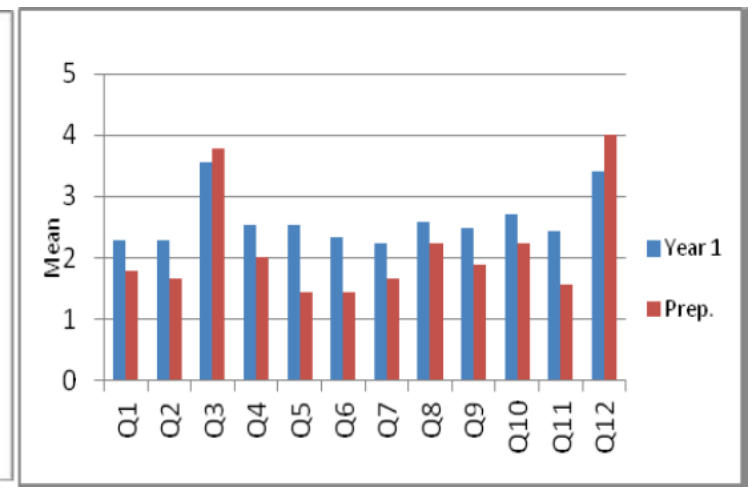

Figure2.

$(P<0.05)$

Table1. Survey Questionnaire

\begin{tabular}{|l|l|}
\hline Q1 & I like using E-Learning for my Business courses \\
\hline Q2 & $\begin{array}{l}\text { I think the teacher's application of E-Learning in teaching Business courses helps me improve my } \\
\text { skills and knowledge }\end{array}$ \\
\hline
\end{tabular}




\begin{tabular}{|l|l|}
\hline Q3 & I think the teacher's application of E-Learning in teaching Business courses is not useful \\
\hline Q4 & I think my grades will improve by using E-Learning for Business courses \\
\hline Q5 & $\begin{array}{l}\text { I find Business courses easier when the teacher uses E-Learning } \\
\text { in teaching }\end{array}$ \\
\hline Q6 & $\begin{array}{l}\text { I hope teachers of Business courses continue to use E-Learning in their } \\
\text { teaching }\end{array}$ \\
\hline Q7 & $\begin{array}{l}\text { Using E-Learning for Business courses is more interesting } \\
\text { than the traditional method }\end{array}$ \\
\hline Q8 & E-Learning makes me more interested in learning Business courses \\
\hline Q9 & $\begin{array}{l}\text { By using E-Learning for Business courses, the opportunity of } \\
\text { interaction with the teacher is enhanced }\end{array}$ \\
\hline Q10 & $\begin{array}{l}\text { By using E-Learning for Business courses, the opportunity of } \\
\text { interaction with my classmates is enhanced }\end{array}$ \\
\hline Q11 & $\begin{array}{l}\text { Using E-Learning for Business courses encourages me to } \\
\text { continue learning on the Internet by myself }\end{array}$ \\
\hline Q12 & I am unwilling to learn English modules through using E-Learning \\
\hline
\end{tabular}

Analysis of the collected data revealed that E-learning is considered more effective than the use of traditional teaching approaches in assisting students enrolled in business courses. In other words, students' perception and awareness of the course's learning content provided via E-Learning platform as BBL is much compelling of the same content through the use of traditional ways of teaching. This success and impact can be referred to a set of characteristics related to E-Learning' advanced technology. According to Smedley (2010), the adoption of e-learning provides the institutions and students flexibility of time and place of delivery or receipt of according to learning information.

A key role in the collective motivation process is awareness of needs. If an individual or the team has a clear idea of what it needs, this entails the emergence of motivation to commit certain actions. If the needs are not realized, the motivation for any activity can not appear. As it is seen from the study, the sample participants indicated significant interest towards online activities and E-Learning process comparing to traditional methods of learning. One of these factors is the consideration that E-Learning in all forms could make learning easier and more sufficient. On the other part, the mobility that ELearning depends upon could allow students to interact and debate the learning topic. Besides, ELearning contributes to the support of the interactive characteristics of learning and teaching environment organizing students' role more effective and efficient through the active interaction with the teaching/learning materials via E-Learning platform.

Important to note, that in E-Learning systems, the role of the teacher is not limited only to the process of organizing and monitoring learning. Wagner et al (2008) notes that E-Learning makes available extra prospects for interactivity between students and teachers during content delivery. A significant part consists of psychological and pedagogical processes aimed at motivating students to work in the online environment of training systems. Compared to traditional forms of education, where the role of the teacher's personality is obvious, always in sight, in E-Learning systems students are left alone with the shell (interface) of the teaching system, where the role of the teacher's personality is at first glance absent or expressed only indirectly, with large time diversity. However, in reality, the role of the teacher's personality is not eliminated but takes other forms. Moreover, it is the teacher's personality that can motivate students to work actively in e-learning systems more than other factors. To positively motivating factors when working in electronic systems should be attributed not only the professional competence of the teacher, loyalty to the students, understanding values of the young generation, actual problems but knowledge of cultural dominants common on the Web, traditions and rules that exist in the Internet space. Given the fact that E-Learning systems are the mainstay of the most advanced achievements of computer technology, it is necessary not only to have basic computer literacy but to live in the information society, being its active member, not nominal.

Work in E-Learning systems should be based on the use of established rules and existing traditions in the Internet environment. The more external experience and traditions (sometimes even informal ones) existing on the Web into the e-learning system are transposed, the easier, more effective and more organically the learning process will take, requiring in this case less motivation efforts.

\section{CONCLUSION AND RECOMMENDATION}

The main goal of the present study was to investigate the impact of E-Learning on the development of students' academic achievement and knowledge. Results reported some meaningful findings about 
online education and technology. E-Learning technologies are a mobile and contemporary tool of the teacher-practitioner, a method of forming a new information culture. They allow students to acquire sustainable life skills and work in the information society, readiness and ability to information activities. The learning process becomes flexible, affordable and personalized. It meets the requirements of student-centered learning.

The student-centered educational process, based on the innovativeness of technologies, methods and forms of education, forms the student's autonomy, adequate self-esteem, the desire for self-realization in educational work. Student-centered learning will help students form the competencies they need in a changing labor market and will enable them to become active and responsible citizens.

With the rapid development of society, technology and technology, changes in the nature of information culture, globalization, mass 'internetization' and socialization of services and technologies, a balanced E-Learning that complements full-time education becomes a priority for the development of the education system. E-Learning changes the nature of teacher and student interaction, requires high motivation and self-discipline from the student, opens up new opportunities for the student's creative expression, contains great potential for the implementation of new ideas and projects, for personal development and the implementation of the principles of continuing education.

After analyzing the situation, the following general conclusion can be drawn:

There is a need for a change of orientation for researched HEI: necessary transition from traditional stationary forms of education to mixed forms of education using e-learning format. It is possible to implement the change of the educational paradigm, having a clearly structured motivation system for faculty members and students.

\section{REFERENCES}

[1] Ang, R. P., Gonzalez, M. C. T., Liwag, M. E. C., Santos, B. and Vistro-Yu, C. (2001). Elements of Student Centered Learning. Quezon City, Philippines: Ateneo de Manila University Loyola Schools.

[2] Algahtani, A.F. (2011). Evaluating the Effectiveness of the E-learning Experience in Some Universities in Saudi Arabia from Male Students' Perceptions, Durham theses, Durham University.

[3] Bhuasiri Wannasiri, Xaymoungkhoun Oudone, Zo Hangjung, Jeung Rho Jae, P. Ciganek Andrew, (2012). Critical Success Factors for E-Learning in Developing Countries: A Comparative Analysis between ICTExperts and Faculty, Computers \& Education, 58(2), 843-855.

[4] Cheng, K. A. (2006). Research Study on Students' Level of Acceptance in Applying E-Learning for Business Courses - A Case Study on a Technical College in Taiwan. Journal of American Academy of Business. 8(2), 265-270.

[5] Collins, J., Hammond, M. and Wellington, J. (1997). Teaching and Learning with Multimedia, London: Routledge.

[6] Golonka, E., Bowles, A, Frank, V., Richardson, D., and Freynik, S. (2014). Technologies for Foreign Language Learning: A Review of Technology Types and Their Effectiveness, Computer Assisted Language Learning, 27(1), 70-105, DOI:10.1080/09588221.2012.700315 https://doi.org/10.1080 /09588221.2012.700315.

[7] Housand, B. C., and Housand, A. M. (2012). The Role of Technology in Gifted Students' Motivation. Psychology in the Schools, 49, 706-715. DOI:10.1002/pits.21629.

[8] Huang, C. S., Yang, S. J., Chiang, T. H., and Su, A. Y. (2016). Effects of Situated Mobile Learning Approach on Learning Motivation and Performance of EFL Students. Journal of Educational Technology and Society, 19(1), 263. https://search.proquest.com/docview/1768612513?pq-origsite=gscholar

[9] Hameed, S. Badii, A. and Cullen, A. J. (2008). Effective E-Learning Integration with Traditional Learning in a Blended Learning Environment. European and Mediterranean conference on information system, (25-26).

[10] Isa Figueiraa Ana, Manuel Duarteb António, (2011), Increasing the Quality of Learning through Changes in Motivation, Social and Behavioral Sciences, 29, $1373-1379$.

[11] Klein, D. and Ware, M. (2003). E-learning: New Opportunities in Continuing Professional Development. Learned publishing, 16(1) 34-46.

[12] Kim Kyong-Jee and W. Frick Theodore, (2011), Changes in Student Motivation during Online Learning, Journal of Educational Computing Research, 44, 1 - 23.

[13] Lucas, M., and Moreira, A. (2009). Bridging Formal and Informal Learning-A Case Study on Students' Perceptions of the Use of Social Networking Tools. Learning in the Synergy of Multiple Disciplines, Cress, U., Dimitrova, V., Specht, M. (Eds.). Springer, Germany. 325-337.http://dx.doi.org/10.1007/978-3642-04636-0. 
The Impact of E-Learning Technologies on Student's Motivation: Student Centered Interaction in Business Education

[14] Marc, J. R. (2002). Book Review: E-Learning Strategies for Delivering Knowledge in the Digital Age. Internet and Higher Education, 5, 185-188.

[15] Maltz, L., Deblois, P. andthe EDUCAUSE Current Issues Committee. (2005). Top Ten IT Issues. EDUCAUSE Review, 40(1), 15-28.

[16] O'Neil, H. F., Wainess, R., and Baker, E. L. (2005). Classification of Learning Outcomes: Evidence from the Computer Games Literature. The Curriculum Journal, 16(4), 455-474. http://www.fi.uu.nl/publicaties /literatuur/endnote_ecgbl_935_o_neil.pdf

[17] O’Neill E., Stevens N.T., Clarke E., Cox P., O’Malley B., Humphreys H., (2011), Use of E-Learning to Enhance Medical Students' Understanding and Knowledge of Healthcare-Associated Infection Prevention and Control, Journal of Hospital Infection, 79(4), 368-370.

[18] Oblinger, D. G., and Hawkins, B. L. (2005). The Myth about E-learning. Educause review, 40(3), 56-59.

[19] Prensky, M., (2007). Digital Game-Based Learning. Minnesota: Paragon House St. Paul.

[20] Roblyer, M. D., and Doering, A. H. (2010). Integrating Educational Technology into Teaching. (5th Edition ed.) Boston, MA: Allyn \& Bacon.

[21] Rossi.P.G. (2009). Learning Environment with Artificial Intelligence Elements. Journal of E-Learning and Knowledge Society, 5(1), 67-75.

[22] Rovai Alfred, Ponton Michael, Wighting Mervyn, Baker Jason, (2007), A Comparative Analysis of Student Motivation in Traditional Classroom and E-Learning Courses, International Journal on ELearning 6(3), 413-432.

[23] Song, D., and Bonk, C. J. (2016). Motivational Factors in Self-Directed Informal Learning from Online Learning Resources. Cogent Education, 3(1), 1205838. http://www.Publicationshare.com/pdfs/Cogent _Ed_Song_Bonk_Motiv_Self-Directed_Informal.pdf

[24] Smedley, J.K. (2010). Modelling the Impact of Knowledge Management Using Technology. OR Insight $23,233-250$

[25] Thomas, K.M., O'Bannon, B.W. and Bolton, N. (2013). Cell Phones in the Classroom: Teachers' Perspectives of Inclusion, Benefits, and Barriers. Computers in the Schools, 30(4), 295-308

[26] Wan Zeying, Wang Yinglei, Haggerty Nicole, (2008), Why People Benefit from E-Learning Differently: The Effects of Psychological Processes on E-Learning Outcomes, Information \& Management, 45(80), 513-521.

[27] Wilkinson, M. (2016) Language Learning with ICT. In: Renandya W., Widodo H. (eds) English Language Teaching Today. English Language Education, 5. Springer, Cham. https://doi.org/10.1007/978-3-319-38834-2_18

[28] Woodrow, L. (2017) Motivation in Language Learning. In: Breeze R., Sancho Guinda C. (eds) Essential Competencies for English-medium University Teaching. Educational Linguistics, 27. Springer, Cham. https://link.springer.com/content/pdf/10.1007\%2F978-3-319-40956-6_16.pdf

[29] Wohlfarth, DeDe; Sheras, Daniel; Bennett, Jessica L.; Simon, Bethany; Pimentel, Jody H.; Gabel, Laura E. (2008). Student Perceptions of Learner-Centered Teaching. In Sight: A Journal of Scholarly Teaching, 3. 67-74.

[30] Wlodkowski, R.J. "Adults in Modern Society are on a Lifelong Educational Journey”, 2005. Retrieved from http://userpages.umbc.edu/ koconne1/605TheAdultLearner/elearning.htm

[31] Wagner, N., Hassanein, K. and Head, M. (2008). Who is Responsible for E-learning in Higher Education? A Stakeholders' Analysis. Educational Technology \& Society, 11 (3), 26-36.

[32] Yang, Y. T. C., and Wu, W. C. I. (2012). Digital Storytelling for Enhancing Student Academic Achievement, Critical Thinking, and Learning Motivation: A year-long experimental study. Computers \& education, 59(2), 339-352.

[33] Zohrabi, M., Torabi, M.A., Baybourdiani, P. (2012). Teacher-Centered and/or Student-Centered Learning: English Language in Iran. English Language and Literature Studies 2(3), 12-17.

Citation: Almaz Sandybayev. "The Impact of E-Learning Technologies on Student's Motivation: Student Centered Interaction in Business Education". International Journal of Research in Tourism and Hospitality (IJRTH), vol 6, no. 1, 2020, pp. 16-24. doi: http://dx.doi.org/10.20431/2455-0043.0601002.

Copyright: () 2020 Authors. This is an open-access article distributed under the terms of the Creative Commons Attribution License, which permits unrestricted use, distribution, and reproduction in any medium, provided the original author and source are credited. 